\title{
Effects of Shade Intensity and Duration on Asian Soybean Rust Caused by Phakopsora pachyrhizi
}

A. P. S. Dias, Monsanto Company, St. Louis 63167; X. Li, Iowa State University, Ames, 50011; P. F. Harmon and C. L. Harmon, University of Florida, IFAS Plant Pathology, Gainesville 32611; and X. B. Yang, Iowa State University, Ames

\begin{abstract}
Dias, A. P. S., Li, X., Harmon, P. F., Harmon, C. L., and Yang, X. B. 2011. Effects of shade intensity and duration on Asian soybean rust caused by Phakopsora pachyrhizi. Plant Dis. 95:485-489.

Field studies to quantify the effects of shade intensity and duration on soybean rust caused by Phakopsora pachyrhizi were carried out in Florida in 2006 and 2007. Soybean plants at the V4 stage were inoculated with urediniospores at 2100, 0000, and $0200 \mathrm{~h}$. Inoculated plants were either placed in cages that were covered with shade cloths of different mesh sizes allowing 70,50 , or $20 \%$ transmission of sunlight or were not covered so that the plants received $100 \%$ of sunlight. Plants kept under 20 and $100 \%$ sunlight were sampled 12,18 , and $36 \mathrm{~h}$ after inoculation to determine the in vivo germination percentage of urediniospores and the percentage of germ tubes that formed appres-

soria. In separate experiments, inoculated plants were placed under the shade (20\% sunlight) and moved to unshaded conditions after 1, 2, and 7 days. For all experiments, soybean rust incidence and severity were rated 12 days after inoculation. Higher levels of disease incidence and severity were detected in plants under shade compared with those under full sunlight. Shade duration greater than 2 days favored disease development. Within $36 \mathrm{~h}$, in vivo germination of urediniospores and formation of appressoria were not significantly affected by the treatments. These results may explain why soybean rust is more severe in the lower canopy and shaded areas in the field.
\end{abstract}

Soybean rust (SBR), caused by Phakopsora pachyrhizi Syd. \& P. Syd., is a major soybean fungal disease in many soybean-producing regions worldwide, especially those with warm and rainy weather during the growing season $(4,35,41)$. Severe infections caused by $P$. pachyrhizi can lead to premature defoliation of diseased plants $(4,35,40)$. Significant soybean yield losses result if premature defoliation is $20 \%$ or more at early reproductive stages $(2,35,36,40)$.

Results from laboratory experiments and field observations have suggested that $P$. pachyrhizi is sensitive to light $(5,15,17,20,24,28)$. Reduced germ tube elongation was observed on light-exposed urediniospores of $P$. pachyrhizi, and germ tubes exhibited negative phototropism, which was enhanced by blue light $(17,20)$. Various studies showed that germination was reduced when urediniospores were exposed to direct sunlight $(15,17,35)$. Similar results were found for broad bean rust caused by Uromyces viciae-fabae (16). Isard et al. (15) recently found that exposure to solar radiation at more than $25 \mathrm{MJ} \mathrm{m}^{-2}$ distributed over 2 days could be fatal to urediniospores of $P$. pachyrhizi. The fungus also seems to avoid direct sunlight by producing uredia on the abaxial side of leaves $(4,5,24,27,35)$.

On a regional scale, SBR was usually more severe after extended periods of rain with overcast weather in Brazil (8). It was observed that disease development in temperate zones of Argentina and China coincided with the diminishing intensity of solar radiation due to solar declination in late summer $(11,35)$. In the United States, in 2005 to 2009, the majority of SBR detections in the north-central region were in the late growing season, usually in September $(7,13,22,38)$, when solar radiation intensity was reduced to half of the levels in early summer (June and July; 30). Recent observational evidence showed that peaks of northward movement of $P$. pachyrhizi spores occurred in late May and late August in 2005 and 2006 but spores were still available in the

Corresponding author: X. B. Yang, E-mail: xbyang@iastate.edu

Accepted for publication 23 November 2010.

doi:10.1094/PDIS-11-09-0753

(C) 2011 The American Phytopathological Society north-central region of the United States in June and July (1). Therefore, for SBR in subtropical or temperate regions, sunlight may be an important limiting environmental factor, along with temperature and moisture, in epidemics of SBR.

Although younger plants may be equally susceptible to the pathogen, SBR is usually detected during the reproductive stages $(4,28)$. Research has shown that, after flowering, soybean leaves in a 0.38 -m-row-spaced canopy intercepted over $80 \%$ of incident solar radiation (31). Sunlight in the crop canopy may be determined by geographical location, date, terrain features, landscape, and weather. Although it is virtually impossible to quantitatively control all of these factors, partially controlled sunlight conditions can mimic certain natural environments in which SBR may differ in disease development. However, this topic has not received much attention, particularly in quantified field studies. A quantitative study on the relationship between sunlight and SBR occurrence is needed to better understand the previous laboratory and field observations and to link them to SBR epidemics at a larger scale. This link will then improve the accuracy of SBR risk assessment and disease forecasting.

In this study, sunlight conditions were partially controlled by using shade cloths allowing different percentages of light (transmission levels) to pass, which reduced inbound sunlight to mimic different shading effects in nature. In these partially controlled shaded areas, soybean plants were inoculated with $P$. pachyrhizi and compared with inoculated soybean plants in unshaded areas. The objectives of this study were to quantify the differences in disease intensity resulting from various intensities and durations of the shading.

\section{Materials and Methods}

To obtain inoculum for this study, urediniospores of $P$. pachyrhizi were collected from leaves of several naturally infected kudzu (Pueraria montana var. lobata) plants near Brandon, FL in April 2006 and 2007. The spores were bulked into one collection in each year. More spores were produced and maintained in a greenhouse at the University of Florida (UFL, Gainesville) on plants of soybean 'Mycogen 5N351RR' (maturity group 3.5). At the V2 to V4 stages, the soybean plants were inoculated with fresh urediniospores diluted in distilled water immediately after collection from kudzu leaves. The inoculated soybean plants were incubated in a growth chamber for $24 \mathrm{~h}$ under $100 \%$ humidity and a temperature 
of $23^{\circ} \mathrm{C}$. After that, they were placed in the greenhouse with temperatures of 23 to $28^{\circ} \mathrm{C}$ and watered every 2 days without extra fertilization. To produce soybean plants for the experiments, Mycogen 5N351RR plants were grown in 10-cm-diameter clay pots (four plants per pot) filled with a greenhouse potting mix. Plants were kept in a greenhouse isolated from sources of Phakopsora pachyrhizi urediniospores until the V4 growth stage. The greenhouse temperature was 23 to $28^{\circ} \mathrm{C}$ as well. The plants were watered every 2 days without extra fertilization.

All experiments were set up on a mowed bahiagrass (Paspalum notatum) field at UFL. Immediately before an inoculation, fresh urediniospores were collected from soybean leaves using a cyclone separator (handcrafted at Iowa State University) connected to a vacuum pump. The urediniospores were suspended in sterile distilled water containing one drop of Tween 20 per $50 \mathrm{ml}$. Spore suspensions $(0.1 \mathrm{ml})$ were assessed for percent germination by incubating spores overnight at $25^{\circ} \mathrm{C}$ on $1.5 \%$ water-agar plates. The next morning, urediniospores on the agar plates were stained with aniline blue lactophenol. The first 100 urediniospores observed in a microscope field at $\times 100$ were examined to determine the percentage of germinated urediniospores. A spore was considered germinated when the germ tube was twice the length of the urediniospore.

Shade intensity experiments. Inoculations were performed at 2100,0000 , or $0200 \mathrm{~h}$. Each of eight soybean leaflets per pot received a single drop containing 0.025 or $0.1 \mathrm{ml}$ of spore suspension in 2006 or 2007, respectively. The initial spore concentration was estimated using a hemacytometer. The final concentration of spore suspension was adjusted according to the inoculation volume, so that each leaflet was inoculated with $5 \times 10^{3}$ urediniospores.

Immediately after inoculation, sets of 12 to 16 potted soybean plants were placed on the grass field, either uncovered (full sunlight) or in cages $(1.2$ by 1.2 by $0.7 \mathrm{~m})$ covered with shade cloths allowing different levels of sunlight transmission (T) (i.e., percentage of sunlight, for shading treatments, $\mathrm{T}=70,50$, or $20 \%$ ). The transmission percentage was determined based on measurement from a radiometer (Radiometer PMA2100; Solar Light Co., Glenside, PA) connected to a sensor (Model PMA2140) for global incident solar radiation in a wavelength range of 400 to $1,100 \mathrm{~nm}$. Plants were only watered when necessary. The inoculated leaves were rated 12 days after inoculation. Disease incidence was the percentage of inoculated leaves that had rust lesions. For severity, each diseased leaflet was assessed using a 0-to-4 scale, where $0=$ no lesions, $1=1$ to 2 lesions, $2=3$ to 10 lesions, $3=11$ to 30 lesions, and $4=$ more than 30 lesions.

Inoculations were conducted on 6 days in 2006 and 2007 (Table 1). There were one or two batches of inoculations on each day at different times. The inoculations on 17 June 2007 had only two treatments (20 and $100 \%$ sunlight) while the others had four treatments $(20,50,70$, and $100 \%$ sunlight). Inoculations on each day were treated as one experiment in a completely randomized design with four or two treatments. Each treatment had four to six replications. Disease incidence data for each experiment were analyzed with the SAS generalized linear model procedure (method type 3;
SAS Institute, Cary, NC). Fisher's least significant difference (LSD) was used to determine LSDs among the treatments at $P=$ 0.05 . Disease severity data were analyzed nonparametrically, with an LD-CI Las macro (6) and the combination of RANK and MIXED procedures, to estimate relative treatment effects and confidence intervals at $P=0.05$ based on the ranking of severity rating (32).

Shade duration experiment. Shade duration experiments had a completely randomized design applied to two replicates on 1 September 2006 and to four replicates on 6 June 2007. This experiment was to examine the effect of shade (full sunlight versus $20 \%$ transmission) over different duration periods (1 to 12 days) on disease development of SBR. In both years, sets of 12 or 16 potted soybean plants were inoculated at $2100 \mathrm{~h}$ in the same way as described previously. They were placed either in an open field uncovered (full sunlight) or in shade-cloth-covered cages $(\mathrm{T}=20 \%)$. A number of shaded pots were moved to an open field after 1,2, or 12 days in 2006 and after 1, 2, 7, or 12 days in 2007. At 12 days after inoculation, all the plants were rated for disease incidence and severity in the same manner as for the shade intensity experiment. The data were analyzed in SAS as described previously.

For all experiments above, on the next day following inoculation, leaf temperatures on three to five randomly selected leaflets were measured every $3 \mathrm{~h}$ with a handheld infrared thermometer (Raytek ST60XB; Raytek Co., Santa Cruz, CA). The presence of leaf wetness was visually assessed every hour after sunrise following inoculation by checking for absorption of water. This was accomplished by lightly wiping on randomly sampled soybean leaves from each treatment using Kimwipes (Kimtech Science, Kent, UK). Average incident solar radiation of full sunlight within the wavelength range of 400 to $1,100 \mathrm{~nm}$ was recorded at 5-min intervals using the same data-logger radiometer used to determine transmission level of shade clothes, and the integrated solar radiation $\left(\mathrm{MJ} \mathrm{m}^{-2}\right)$ was estimated for that day.

Spore germination and appressorium formation. To determine whether spore germination of Phakopsora pachyrhizi on soybean leaves was affected by shade, two experiments were conducted on 1 September 2006 and 6 June 2007. Each experiment had four sets of two soybean pots inoculated at $2100 \mathrm{~h}$ as previously described and placed either in an open space (full sunlight) or in shade-cloth-covered cages $(\mathrm{T}=20 \%)$ arranged in a completely randomized design. Aliquots $(0.1 \mathrm{ml})$ of urediniospore suspensions $\left(5 \times 10^{4}\right.$ urediniospores $\left./ \mathrm{ml}\right)$ were incubated overnight on 2.5 -cm-diameter plates containing water agar $(1.5 \%)$ for assessment of urediniospore germination. Five leaflets were sampled from each set of pots 12,18 , and $36 \mathrm{~h}$ after inoculation. Leaf segment samples $\left(2 \mathrm{~cm}^{2}\right)$ excised from the leaflet center were placed on $100 \mathrm{ml}$ of glacial acetic acid and $95 \%$ ethanol (1:1) for clearing at $45^{\circ} \mathrm{C}$. After $2 \mathrm{~h}$, cleared leaf segments were washed twice in distilled water and then stained with aniline blue lactophenol for 10 min. After washing in distilled water to remove excess stain, leaf segments were observed under a compound microscope at $\times 400$. All germinated urediniospores on the leaf samples were examined to determine the percentage of spores exhibiting the following: (i)

Table 1. Description of environmental conditions on the day after inoculation for the experiments conducted in 2006 and 2007 for effects of shade intensity on soybean rust caused by Phakopsora pachyrhizi

\begin{tabular}{|c|c|c|c|c|c|c|}
\hline \multirow[b]{2}{*}{ Date } & \multirow[b]{2}{*}{ Inoculation time ${ }^{b}$} & \multirow[b]{2}{*}{ Sunlight level $(\%)^{\mathrm{c}}$} & \multicolumn{4}{|c|}{ Environmental variables ${ }^{a}$} \\
\hline & & & $\mathbf{I}_{\mathbf{R A D}}$ & $\mathbf{L W}$ & $\mathbf{T}_{\mathbf{d}}$ & $\mathbf{T}_{\mathbf{n}}$ \\
\hline 28 June 2006 & $0200 \mathrm{~h}$ & $20 / 50 / 70 / 100$ & 19.0 & 8.0 & 27.5 & $\ldots$ \\
\hline 10 July 2006 & $2100 / 0000 \mathrm{~h}$ & $20 / 50 / 70 / 100$ & $\ldots$ & 7.5 & 27.0 & 23.0 \\
\hline 31 August 2006 & $0000 / 0200 \mathrm{~h}$ & $20 / 50 / 70 / 100$ & 14.5 & 9.5 & 27.5 & 25.5 \\
\hline 1 September 2006 & $2100 \mathrm{~h}$ & $20 / 50 / 70 / 100$ & 20.5 & 10.0 & 28.5 & 25.0 \\
\hline 6 June 2007 & $2100 \mathrm{~h}$ & $20 / 50 / 70 / 100$ & 21.0 & 6.0 & 27.5 & 24.0 \\
\hline 17 June 2007 & $2100 / 0200 \mathrm{~h}$ & $20 / 100$ & 25.5 & 6.0 & 28.5 & 24.0 \\
\hline
\end{tabular}

a Environmental variables were monitored in unshaded conditions and included incident solar radiation $\left(\mathrm{I}_{\mathrm{RAD}}, \mathrm{MJ}^{-2} \mathrm{day}^{-1}\right)$, number of hours of leaf wetness $(\mathrm{LW})$, average day air temperature $\left(\mathrm{T}_{\mathrm{d}}{ }^{\circ} \mathrm{C}\right)$, and night air temperature $\left(\mathrm{T}_{\mathrm{n}}{ }^{\circ} \mathrm{C}\right)$.

${ }^{b}$ Different soybean plants were inoculated at different times during the night, then placed under shade to receive different proportions of sunlight.

c Percentage of the sunlight transmission through shade clothes used to control sunlight level in a treatment; $100 \%$ represents full sunlight. 
germ tube only (at least twice the length of the urediniospore) and (ii) germ tube with appressorium. Pots with inoculated soybean plants were then maintained under the shade treatments for 12 days and were evaluated for SBR severity. The data were analyzed in SAS as described previously.

\section{Results}

Effects of shade intensity. Shade intensity had a significant effect on SBR incidence in almost all the experiments conducted in 2006 and 2007 (Table 2). Although incidence level varied among different experiments, it was generally greater in shaded conditions compared with full sunlight in each experiment (Tables 2 and 3). In the experiment on 6 June 2006, there was no significant differences of mean disease incidence (Table 3) among the four treatments using Fisher's LSD at $P=0.05$; however, a significant positive linear correlation $(r=0.5541$ and $P=0.0258)$ between the incidence and shade intensity was found. For the infected leaves in each experiment, those in shaded treatments had higher disease severity ratings and larger relative treatment effects compared with those in full sunlight (Table 4).

Effects of shade duration. In general, increasing shade duration resulted in significantly greater SBR incidence, particularly in 2006 (Table 5). In 2007, the overall disease incidence level was lower than that in 2006, and SBR was detected only in those treatments where shading occurred for at least 2 days. In both experiments, the relative treatment effects on those infected leaves were similar for the treatments receiving 12 days of shading.

It was observed that disease incidence decreased when daily solar radiation was greater than $10 \mathrm{MJ} \mathrm{m}^{-2}$ (Fig. 1). Although this trend was observed in all experiments, the reduction in SBR incidence was more pronounced in the experiments conducted in June. Leaf temperatures were similar, mostly in a range of 1 to $2^{\circ} \mathrm{C}$ difference, for leaves exposed to different shade intensities in each experiment. The highest leaf temperatures, around $31 \pm 1^{\circ} \mathrm{C}$, were observed in the experiments in September 2006. In June 2006 and 2007, the highest leaf temperatures were around 29 and $26 \pm 1{ }^{\circ} \mathrm{C}$, respectively. The duration of leaf wetness was usually similar

Table 2. Results of generalized linear model analysis for experiments to determine the effect of shade intensity on soybean rust caused by Phakopsora pachyrhizi

\begin{tabular}{llcc}
\hline Date $^{\mathbf{a}}$ & Effect & $\boldsymbol{F}$ value & $\boldsymbol{P}>\boldsymbol{F}$ \\
\hline 28 June 2006 & Shade & 32.06 & $<0.0029$ \\
10 July 2006 & Shade & 30.72 & $<0.0001$ \\
31 August 2006 & Shade & 11.12 & 0.0009 \\
1 September 2006 & Shade & 10.43 & 0.0232 \\
6 June 2007 & Shade & 2.01 & $0.1662^{\mathrm{b}}$ \\
17 June 2007 & Shade & 3.17 & 0.0464 \\
\hline
\end{tabular}

${ }^{a}$ Experiments conducted on each date were analyzed separately because a preliminary analysis across all experiments had a significant $(P<0.0001)$ date-shade interaction resulting from differences in disease incidence across experiments.

${ }^{\mathrm{b}}$ Shade intensity did not show significant effect in this experiment. among the shade intensity treatments, with shaded treatments exhibiting an additional half-hour of leaf wetness on average compared with the unshaded treatments. The surface of inoculated leaves in shaded and unshaded treatments was usually completely dry by $1000 \mathrm{~h}$ the next day.

Spore germination and appressorium formation. At $12 \mathrm{~h}$ after inoculation, spore germination was approximately $80 \%$ on both agar plates and leaf surfaces, and most of the germinated urediniospores produced appressoria. There were no significant increases in germination or appressorium formation from 12 to $36 \mathrm{~h}$ after inoculation (data not shown). Also, there were no significant differences in germination or appressorium formation on leaves incubated in full sunlight or under shade $(\mathrm{T}=20 \%$; data not shown). These results indicate that most germination and appressorium formation occurred during the first dew period following inoculation and that these processes are not affected by light intensity during the day.

\section{Discussion}

Our results showed that SBR was consistently more prevalent and more severe under shaded conditions and that the disease was favored by longer durations of shading. The consistency among experiments demonstrated the importance of low light intensity in association with development of SBR. It is well known that $P$. pachyrhizi develops on abaxial surfaces of hosts $(4,35)$ and that soybean leaves intercept up to $80 \%$ of the incident solar radiation reaching the lower canopy in commercial fields (31). In conjunction with these facts, the results of this study help explain why the disease is usually concentrated on soybean leaves in the lower canopy post flowering or in shaded patches in commercial fields. Furthermore, sunlight intensity and day length decrease rapidly toward the end of the growing season, particularly in high-latitude regions, and these reductions in light are likely favorable for SBR. Thus, the results from this study can also explain why SBR is frequently reported in the late season $(7,13,22,38)$.

In addition to shade, other environmental conditions that are favorable to disease development, such as moderate and consistent temperatures, high humidity, and prolonged leaf wetness, are often present in the lower canopy. This experiment was designed to minimize the effects of these variables among the shade treatments by using potted plants. Average night-time leaf temperatures (Table 1) were usually within the favorable range for germination and infection $(4,21,23,29)$. The minimum period of leaf wetness required for spore germination $(23,24)$ was observed in all treatments in the study. Therefore, it is unlikely that these other environmental variables confounded the effects of shading on SBR incidence and severity.

Normally, SBR appressoria are initially observed $6 \mathrm{~h}$ after inoculation, and penetration pegs are formed within $12 \mathrm{~h}(19,26)$. In this study, on the morning following inoculation, most urediniospores on the leaf surface were germinated, with developing appressoria or penetration pegs. No further increase of germination and penetration structure formation after the first $12 \mathrm{~h}$ may have been due to the absence of leaf wetness after sunrise or the inhibi-

Table 3. Mean incidence (percentage of leaves with rust) of soybean rust caused by Phakopsora pachyrhizi estimated on inoculated soybean plants receiving different percentage of sunlight in the six experiments

\begin{tabular}{|c|c|c|c|c|c|c|}
\hline \multirow[b]{3}{*}{ Sunlight (\%) } & \multicolumn{6}{|c|}{ Disease incidence (\%) in each experiment } \\
\hline & \multicolumn{4}{|c|}{2006} & \multicolumn{2}{|c|}{2007} \\
\hline & 28 June & 10 July & 31 August & 1 September & 6 June & 17 June $^{\mathrm{a}}$ \\
\hline 20 & 39.5 & 32.3 & 91.7 & 99.0 & 10.9 & 95.0 \\
\hline 50 & 48.5 & 44.0 & 93.8 & 100.0 & 7.9 & $\ldots$ \\
\hline 70 & 29.5 & 29.3 & 64.6 & 95.8 & 1.6 & $\ldots$ \\
\hline 100 & 4.5 & 3.0 & 26.9 & 74.0 & 0.0 & 58.4 \\
\hline $\mathrm{LSD}^{\mathrm{b}}$ & 13.2 & 9.6 & 37.9 & 11.3 & $11.2^{\mathrm{c}}$ & 19.9 \\
\hline
\end{tabular}

a Only two treatments, sunlight percentage $=20 \%$ and $100 \%$ were used for the experiment on this day.

${ }^{\mathrm{b}}$ LSD represents least significant differences among treatments at $P=0.05$.

${ }^{\mathrm{c}}$ Differences among the treatments were not significant in this experiment. 
tion from sunlight even at a low level. However, disease severities were still significantly $(P<0.001)$ lower on unshaded soybean plants compared with shaded ones after 12 days. The effect of shade duration (Table 5) suggests that sunlight likely affects postgermination or post-infection processes in SBR. Similarly, there were reports of increasing numbers of lesions on soybean plants kept in the dark for as long as $16 \mathrm{~h}$ following inoculation, although

Table 4. Severity of soybean rust caused by Phakopsora pachyrhizi estimated on plants in unshaded (full sunlight) and shaded (20\% sunlight) environments 12 days after inoculation for experiments conducted on 1 September 2006 and 6 June 2007

\begin{tabular}{lccc}
\hline & \multicolumn{3}{c}{ Measurement of severity $^{\mathbf{a}}$} \\
\cline { 2 - 4 } Date, treatment & Median & Rank & RE (95\% CI) $\mathbf{~}^{\mathbf{b}}$ \\
\hline 1 September 2006 & & 18.0 & $0.73(0.69-0.77)$ \\
$\quad$ Shade & 4 & 7.0 & $0.27(0.23-0.31)$ \\
$\quad$ No shade & 3 & & \\
6 June 2007 & 3 & 8.5 & $0.67(0.51-0.73)$ \\
Shade & 2 & 4.5 & $0.33(0.27-0.48)$ \\
$\quad$ No shade &
\end{tabular}

${ }^{a}$ Estimates include median severity rating (Median), mean rank of severity rating, and relative treatment effects (REs) with respective confidence intervals (CIs) at 95\%.

b REs were calculated based on nonparametric ranking of treatment severity rating. Treatments with larger estimates of REs tend to exhibit greater severity ratings compared with the averages of all treatments.

Table 5. Effects of shade duration after inoculation on incidence and severity of soybean rust caused by Phakopsora pachyrhizi

\begin{tabular}{lcccc}
\hline & & \multicolumn{3}{c}{ Measurement of severity } \\
\cline { 3 - 5 } Date, days $^{\mathbf{b}}$ & Incidence (\%) & Median & Rank & RE (95\% CI) \\
\hline 1 September 2006 & & & & \\
0 & 26.9 & 2 & 3.5 & $0.38(0.38-0.39)$ \\
1 & 55.9 & 2 & 3.5 & $0.38(0.38-0.39)$ \\
2 & 64.2 & 2 & 3.5 & $0.38(0.38-0.39)$ \\
12 & 91.7 & 4 & 7.5 & $0.88(0.88-0.89)$ \\
LSD & $\ldots$ & 16.1 & $\ldots$ & $\ldots$ \\
6 June 2007 & & & & \\
0 & 0.0 & 0 & 6.5 & $0.30(0.24-0.38)$ \\
1 & 0.0 & 0 & 6.5 & $0.30(0.24-0.38)$ \\
2 & 3.1 & 0 & 9.9 & $0.47(0.24-0.72)$ \\
7 & 13.3 & 2 & 13.9 & $0.67(0.41-0.82)$ \\
12 & 10.9 & 2 & 15.8 & $0.76(0.58-0.85)$ \\
LSD & $\ldots$ & 9.2 & $\ldots$ & $\ldots$ \\
\hline
\end{tabular}

${ }^{a}$ Estimates include median severity rating (Median), mean rank of severity rating (Rank), and relative treatment effects (REs) with respective confidence intervals (CIs) at $95 \%$.

${ }^{b}$ Days in the shade. LSD represents least significant differences of incidence for treatments in the same experiment at $P=0.05$.

${ }^{c}$ REs were calculated based on nonparametric ranking of treatment severity rating. Treatments with larger estimates of REs tend to exhibit greater severity ratings compared with the averages of all treatments.

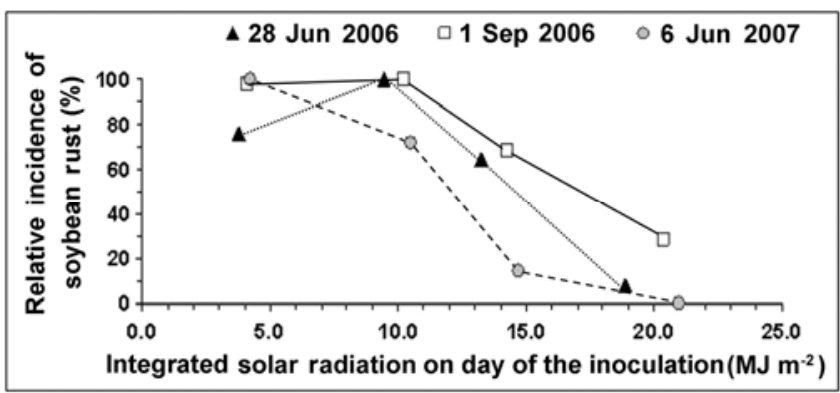

Fig. 1. Relative incidence of soybean rust caused by Phakopsora pachyrhizi at different daily solar radiation intensities resulting from shading to mimic different light intensities in three experiments. Incidence values were standardized to the highest values observed in each experiment. penetration rates remained constant after $8 \mathrm{~h}$ of darkness (3). In nature, some spores may still be able to germinate or to finish the infection process during the day if rainy or overcast weather provides a prolonged low-light condition. Some nongerminated urediniospores that survived under reduced solar radiation may also germinate during the following nights when leaf wetness is again present. Further investigation is needed.

The physiologic mechanism of the interactions of $P$. pachyrhizi and soybean associated with light is unclear. Some soybean defense mechanisms are elicited by light, which might explain possible effects of sunlight on $P$. pachyrhizi colonization $(12,34,37)$. Similar $P$. pachyrhizi colony growth and haustorium formation were observed on susceptible and resistant soybean cultivars for as long as $24 \mathrm{~h}$ after inoculation when plants were kept in the dark (25). However, only susceptible cultivars had increased fungal growth and haustorium formation when the plants were exposed to light $(18,25)$. The delay in colony growth on resistant cultivars was associated with increasing numbers of necrotic host cells near the infection loci. This reaction was attributed to the activation of host defense mechanisms such as accumulation of the phytoalexin glyceollin in resistant cultivars $(9,18,25)$. Furthermore, several studies have reported that the production of glyceollin and precursors in soybean is regulated by light $(12,34,37)$. Soybean seedlings incubated for more than $12 \mathrm{~h}$ under light had a 30 times higher glyceollin concentration and exhibited greater resistance to Phytophthora megasperma f. sp. glycinea than seedlings incubated in the dark (37). Our observations and experimental results consistently suggest that SBR is more severe under conditions of shade, which suggested that the effects of sunlight on pathogen-host interactions may play a vital role.

We observed reduced disease incidence at daily solar radiation intensities greater than $10 \mathrm{MJ} \mathrm{m}^{-2}$. Similar solar radiation levels are often observed in the fall at temperate latitudes or on cloudy days in the tropics (30). After the summer solstice, which occurs in June and December in the northern and southern hemispheres, respectively, day length becomes progressively shorter, with weaker incident radiation. This effect is particularly noticeable toward the fall season in temperate latitudes (14). In summer 2006, an average daily solar radiation intensity of $15 \mathrm{MJ} \mathrm{m}^{-2}$ was observed in the central United States (30). Daily radiation levels dropped to $8 \mathrm{MJ}$ $\mathrm{m}^{-2}$ in the fall, coinciding with the time that SBR occurrences expanded northward in the past few years according to disease monitoring data on the Pest Information Platform for Extension and Education (http://sbr.ipmpipe.org). In this study, only disease development within 12 days after inoculation was assessed. Given that SBR is a polycyclic disease with a short latent period (7 to 14 days) under favorable conditions $(4,35)$, differences in disease development resulting from daily changes of sunlight will be accumulated over the growing season. Thus, the occurrences of SBR in late summer in high-latitude regions where day length is longer (equivalent to less shading in every day) than tropic regions in early summer also may be partially explained by these results $(4,7,35)$

On a regional scale, rain clouds and atmospheric humidity can also contribute to reduced solar radiation by processes of absorption or reflection $(10,39)$. Indeed, SBR outbreaks were reportedly most severe in regions with frequent rainfall distributed over many rainy and cloudy days $(9,33,35)$. Investigations of the synergetic effects of these factors on regional SBR epidemics may facilitate a better disease-forecasting model system and better management of this disease.

\section{Literature Cited}

1. Barnes, C. W., Szabo, L. J., and Bowersox, V. C. 2009. Identifying and quantifying Phakopsora pachyrhizi spores in rain. Phytopathology 99:328338.

2. Blessitt, J. B., Poston, D. H., Sciumbato, G. L., Coleman, R. T., Doty, H. C., Eubank, T. W., Kyei-Boahen, S., Moore, W. R., and Spinks, B. L. 2007. Impact of fungicide and defoliation timing on soybean yield. Page 17 in: Proc. Southern Soybean Disease Workers, St. Louis.

3. Bonde, M. R., Melching, J. S., and Bromfield, K. R. 1976. Histology of the 
suspect-pathogen relationship between Glycine max and Phakopsora pachyrhizi, the cause of soybean rust. Phytopathology 66:1290-1294.

4. Bromfield, K. R. 1984. Soybean Rust. Monograph No 11. American Phytopathological Society, St. Paul, MN.

5. Bromfield, K. R., Melching, J. S., and Kingsolver, C. H. 1980. Virulence and aggressiveness of Phakopsora pachyrhizi isolates causing soybean rust. Phytopathology 70:17-21.

6. Brunner, E., Domhof, S., and Langer, F. 2002. Nonparametric Analysis of Longitudinal Data in Factorial Experiments. John Wiley \& Sons, New York.

7. Christiano, R. S. C., and Scherm, H. 2007. Quantitative aspects of the spread of Asian soybean rust in the southeastern United States, 2005 to 2006. Phytopathology 97:1428-1433.

8. Del Ponte, E. M., Godoy, C. V., Li, X., and Yang, X. B. 2006. Predicting severity of Asian soybean rust epidemics with empirical rainfall models. Phytopathology 96:797-803.

9. De Mortel, M. V., Recknor, J. C., Graham, M. A., Nettleton, D., Dittman, J. D., Nelson, R. T., Godoy, C. V., Abdelnoor, R. V., Almeida, A. M. R., Baum, T. J., and Whitham, S. A. 2007. Distinct biphasic mRNA changes in response to Asian soybean rust infection. Mol. Plant-Microbe Interact. 20:887-899.

10. Dogniaux, R. 1993. Parameters of the environment influencing the radiation climate of a site and their evaluation. Pages 15-34 in: Prediction of Solar Radiation in Areas with a Specific Microclimate. R. Dogniaux, ed. Kluwer Academic Publishers, Dordrecht, The Netherlands.

11. Formento, A. N., and Gieco, I. B. 2007. Estadísticas de la detección de roya Asiática de la soja (Phakopsora pachyrhizi) en cultivos durante el ciclo agrícola 2005/06. Instituto Nacional de Tecnología Agropecuaria, INTA Parana, Entre Ríos, Argentina. Online publication.

12. Graham, T. M., and Graham, M. Y. 1991. Glyceollin elicitors induce major but distinctly different shifts in isoflavonoid metabolism in proximal and distal soybean cell populations. Mol. Plant-Microbe Interact. 4:60-68.

13. Hartman, G. L., Hines, R. A., Faulkner, C. D., Lynch, T. N., and Pataky, N. 2007. Late season occurrence of soybean rust caused by Phakopsora pachyrhizi on soybean in Illinois. Plant Dis. 91:466.

14. Iqbal, M. 1983. An Introduction to Solar Radiation. Academic Press, Ontario, Canada.

15. Isard, S. A., Dufault, N. S., Miles, M. R., Hartman, G. L., Russo, J. M., De Wolf, E. D., and Morel, W. 2006. The effect of solar irradiance on the mortality of Phakopsora pachyrhizi urediniospores. Plant Dis. 90:941-945.

16. Joseph, M. E., and Hering, T. F. 1997. Effects of environment on spore germination and infection by broad bean rust (Uromyces viciae-fabae). J. Agric. Sci. 128:73-78.

17. Keogh, R. 1974. Phakopsora pachyrhizi Syd.: the causal agent of soybean rust. Aust. Plant Pathol. Soc. Newsl. 3:5

18. Keogh, R. C., Deverall, B. J., and McLeod, S. 1980. Comparison of histological and physiological responses to Phakopsora pachyrhizi in resistant and susceptible soybean. Trans. Br. Mycol. Soc. 74:329-333.

19. Koch, E., Ebrahim-Nesbat, F., and Hoppe, H. H. 1983. Light and electron microscopic studies on the development of soybean rust (Phakopsora pachyrhizi Syd.) in susceptible soybean leaves. J. Phytopathol. 106:302-320.

20. Koch, E., and Hoppe, H. H. 1987. Effect of light on uredospore germination and germ tube growth of soybean rust (Phakopsora pachyrhizi Syd.). J. Phytopathol. 119:64-74.

21. Kochman, J. K. 1979. The effect of temperature on development of soybean rust (Phakopsora pachyrhizi). Aust. J. Agric. Res. 30:273-277.

22. Li, X., Engelbrecht, C. J., Mueller, D. S., and Yang, X. B. 2008. First report of soybean rust caused by Phakopsora pachyrhizi in Iowa and its statewide occurrence. Plant Dis. 92:975.
23. Marchetti, M. A., Melching, J. S., and Bromfield, K. R. 1976. The effects of temperature and dew period on germination and infection by urediospores of Phakopsora pachyrhizi. Phytopathology 66:461-463.

24. Marchetti, M. A., Uecker, F. A., and Bromfield, K. R. 1975. Uredial development of Phakopsora pachyrhizi in soybeans. Phytopathology 65:822-823.

25. McLean, R. J. 1979. Histological studies of resistance to soybean rust, Phakopsora pachyrhizi Syd. Aust. J. Agric. Res. 30:77-84.

26. McLean, R. J., and Byth, D. E. 1981. Histological studies of the pre-penetration development and penetration of soybean by rust, Phakopsora pachyrhizi Syd. Aust. J. Agric. Res. 32:435-443.

27. Melching, J. S., Bromfield, K. R., and Kingsolver, C. H. 1979. Infection, colonization, and uredospore production on Wayne soybean by four cultures of Phakopsora pachyrhizi, the cause of soybean rust. Phytopathology 69:1262-1265.

28. Melching, J. S., Dowler, W. M., Koogle, D. L., and Royer, M. H. 1988. Effects of plant and leaf age on susceptibility of soybean to soybean rust. Can. J. Plant Pathol. 10:30-35.

29. Melching, J. S., Dowler, W. M., Koogle, D. L., and Royer, M. H. 1989. Effects of duration, frequency, and temperature of leaf wetness periods on soybean rust. Plant Dis. 73:117-122.

30. Pinker, R.T., Tarpley, J. D., Laszlo, I., Mitchell, K.E., Houser, P.R., Wood, E.F., Schaake, J.C., Robock, A., Lohmann, D., Cosgrove, B.A., Sheffield, J., Duan, Q., Luo, L., and Higgins, R.W. 2003. Surface radiation budgets in support of the GEWEX Continental Scale International Project (GCIP) and the GEWEX Americas Prediction Project (GAPP), including the North American Land Data Assimilation System (NLDAS) project. J. Geophys. Res. 108:8844-8861.

31. Sauer, T. J., Singer, J. W., Prueger, J. H., DeSutter, T. M., and Hatfield, J. L. 2007. Radiation balance and evaporation partitioning in a narrow-row soybean canopy. Agric. For. Meteorol. 145:206-214

32. Shah, D. A., and Madden, L. V. 2004. Nonparametric analysis of ordinal data in designed factorial experiments. Phytopathology 94:33-43.

33. Siqueri, F. V. 2005. Ocorrência da ferrugem Asiática (Phakopsora pachyrhizi) no estado de Mato Grosso-Safra 2004/2005. Pages 93-99 in: Proc. Workshop Brasileiro sobre ferrugem Asiática, Uberlândia, Minas Gerais, Brazil.

34. Stossel, P. 1982. Glyceollin production in soybean. J. Phytopathol. 105:109119.

35. Tan, Y. J., Yu, Z. L., and Yang, C. Y. 1996. Soybean Rust. China Agriculture Press, Beijing.

36. Vakili, N. G. 1979. Field survey of endemic leguminous hosts of Phakopsora pachyrhizi in Puerto Rico. Plant Dis. Rep. 63:931-935.

37. Ward, E. W. B., and Buzzell, R. I. 1983. Influence of light, temperature and wounding on the expression of soybean genes for resistance to Phy tophthora megasperma f. sp. glycinea. Physiol. Plant Pathol. 23:401-409.

38. Watson, S. R., Giesler, L. J., Ziems, A. D., and Brovont, T. E. 2008. First report of soybean rust caused by Phakopsora pachyrhizi in Nebraska. Plant Dis. 92:1588.

39. Welch, R. M., Cox, S. K., and Davis, J. M. 1980. Solar Radiation and Clouds. Meteorological Monographs. Vol. 17. American Meteorological Society, Boston.

40. Yang, X. B., Royer, M. H., Tschanz, A. T., and Tsai, B. Y. 1990. Analysis and quantification of soybean rust epidemics from seventy-three sequential planting experiments. Phytopathology 80:1421-1427.

41. Yorinori, J. T., Paiva, W. M., Frederick, R. D., Costamilan, L. M., Bertagnolli, P. F., Hartman, G. E., Godoy, C. V., and Nunes-Junior, J. 2005. Epidemics of soybean rust (Phakopsora pachyrhizi) in Brazil and Paraguay from 2001 to 2003. Plant Dis. 89:675-677. 